\title{
High prevalence of vitamin D deficiency and its association with metabolic disorders in elderly patients
}

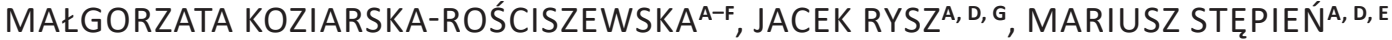 \\ Department of Nephrology, Hypertension and Family Medicine, Medical University of Lodz, Poland
}

A - Study Design, B - Data Collection, C - Statistical Analysis, D - Data Interpretation, E - Manuscript Preparation, F - Literature Search, G - Funds Collection

Summary Background. Vitamin D is considered to be an important co-factor of metabolic processes. However, the available data is ambiguous. Some data indicates an important role of vitamin D in adipocyte metabolism, and hence also in obesity - a well-known risk factor of diabetes mellitus and cardiovascular diseases (CVD).

Objectives. To assess the prevalence of vitamin D deficiency and to evaluate the relationship between serum $25(\mathrm{OH}) \mathrm{D}$ concentration and metabolic disorders in elderly patients attending primary care.

Material and methods. This observational study was performed on 110 elderly patients: 88 females, 22 males, Caucasian, $>60$ years. A questionnaire was completed concerning lifestyle and chronic diseases. Clinical examination, anthropometric measurements and laboratory tests $(25(\mathrm{OH}) \mathrm{D}$, lipids, glycemia, blood morphology, serum creatinine, PTH) were performed. BMI and WHR were calculated. Patients reporting physical activity (walking, Nordic walking, swimming, cycling, other) $\geq 150$ minutes per week were classified as "physically active".

Results. Vitamin D deficiency (25(OH)D $<30 \mathrm{ng} / \mathrm{ml} ;<75 \mathrm{nmol} / \mathrm{l})$ was found in $84.5 \%$, extreme deficiency $(<10 \mathrm{ng} / \mathrm{ml} ;<25 \mathrm{nmol} / \mathrm{l})$ in $6.3 \%$. A significant correlation between serum vitamin $D$ deficiency and visceral obesity was found $(p=0.02)$. No correlation was found with BMI, physical activity, lipids, diabetes or CVD.

Conclusions. Vitamin D deficiency was found to be highly prevalent in the examined group of elderly people. Visceral obesity in the elderly is associated with vitamin D deficiency. Vitamin D supplementation may supposedly contribute to prevention of obesity and its treatment.

Key words: vitamin D deficiency, metabolic disorders, elderly people.

Koziarska-Rościszewska M, Rysz J, Stępień M. High prevalence of vitamin D deficiency and its association with metabolic disorders in elderly patients. Fam Med Prim Care Rev 2017; 19(4): 372-376, doi: https://doi.org/10.5114/fmpcr.2017.70809.

\section{Background}

Vitamin D is suspected to be an important co-factor of metabolic processes, acting, in fact, as a hormone [1]. The best known role of vitamin $D$ is its participation in bone metabolism [2]. Vitamin D receptors (VDR) have been found in multiple tissues and organs important for bone mineral homeostasis (e.g. bones, kidneys, parathyroid glands), as well as in those not involved in such processes (e.g. pancreatic beta-cells, cells of the immune system) - influencing the appropriate functions of the organism. Vitamin D deficiency is believed to play a role in the pathogenesis of neoplasms and psychiatric disorders. It may also increase all-cause mortality [3]. There is more and more data on the important role of vitamin $D$ in the metabolism of adipocytes, and thereby in obesity - an increasing worldwide threat. The number of obese people has exceeded 1.5 billion worldwide, and it appears in a younger and younger population [4]. The worldwide obesity prevalence in adults ranges from 5 to $75 \%$ [5]. Excess body mass is also present in children and adolescents (e.g. 10-30\% in Europe) [5].

In Poland, there is also an increasing number of people with overweight and obesity. It is estimated that nearly $50 \%$ of Polish adults are overweight, and $20 \%$ are obese [6]. This percentage is even higher in the elderly (overweight $>40 \%$; obesity $>30 \%$ ) [7]. Overweight and obesity also concerns Polish children and adolescents (15-20\% and 4\%, respectively) [6].

Obesity is one of the most important risk factors of diabetes mellitus (DM) and cardiovascular diseases (CVD) and their serious consequences.
There is increasing evidence that, owing to VDR presence in different organs, vitamin $D$ is of great significance in the pathogenesis of "civilization-related diseases", such as DM, CVD, metabolic syndrome (MS), heart failure, hypertension (HA) and vascular inflammation $[1,3]$. The influence of vitamin $D$ deficiency on atherosclerotic vascular changes is a complex phenomenon. A decreased serum vitamin $D$ concentration leads to increased activity of the renin-angiotensin-aldosterone system (RAAS), insulin-resistance (IR), inflammation and, finally, to CVD $[1,8]$.

There are two general sources of vitamin $D$ in humans: sunlight (UV irradiation), which is responsible for the majority of vitamin D supply, and food rich in this fat soluble vitamin (e.g. fatty sea fish).

Vitamin D3 (cholecalciferol) is obtained through conversion of 7-dehydrocholesterol in the human skin upon UVB radiation. It is converted in the subsequent processes to $25(\mathrm{OH}) \mathrm{D}$ (calcidiol) by the liver, and next to $1,25(\mathrm{OH})_{2} \mathrm{D}$ (calcitriol) by the kidneys. Calcitriol is considered to be the active form of vitamin $D$, but the calcidiol concentration is found to correlate better with the actual serum vitamin $D$ status and is regarded to be a clinically appropriate indicator [1]. A favorable $25(\mathrm{OH}) \mathrm{D}$ level starts at $30 \mathrm{ng} / \mathrm{mL}(75 \mathrm{nmol} / \mathrm{L})$; severe deficiency is recognized at 10 $\mathrm{ng} / \mathrm{mL}(25 \mathrm{nmol} / \mathrm{L})$ [9].

Vitamin $D$ deficiency is a worldwide problem and a public health concern. It is estimated that nearly $90 \%$ of the European and approx. $75 \%$ of the US adult population is vitamin D deficient/insufficient [10]. It is hypothesized that a decrease of vitamin $D$ serum concentration can increase the prevalence of obesity. A number of studies have revealed an association be- 
tween obesity and vitamin $\mathrm{D}$ status, i.e. an increase in adiposity correlating with lower serum $25(\mathrm{OH}) \mathrm{D}[11,12]$. It is considered that adiposity may even be primarily responsible for low vitamin $D$ levels [13]. Obese people are more likely to present suboptimal 25(OH)D [14].

Poland is one of the largest European countries, and its society is aging. The number of people $>65$ years is $15 \%$ and is still increasing [15]. Data on vitamin D serum concentration in Polish elderly is scarce. The prevalence of overweight and obesity increases with age and attains the highest percentage in 60-69-year-old Polish seniors ( $44 \%$ overweight, $28 \%$ obesity) [15]. Similar data came from the Pol-Senior study (2007-2011), which showed $40.8 \%$ overweight and $31.9 \%$ obesity in patients aged $>65$ [7].

\section{Objectives}

Elderly people with CVD constitute a significant number of patients at family medicine practices worldwide. Therefore, the aim of our study was to assess the prevalence of vitamin D deficiency and to evaluate the relationship between serum vitamin $D$ concentration and metabolic disorders (especially obesity) in the group of patients aged $>60$.

\section{Material and methods}

The study was conducted on a group of 110 primary care patients ( 88 females, 22 males), Caucasian, $>60$ years old. In each person, a questionnaire was completed concerning lifestyle (physical activity, smoking, diet) and chronic diseases. Clinical examination, anthropometric measurements and laboratory tests $(25(\mathrm{OH}) \mathrm{D}$, lipids, glycemia, morphology, PTH) were per- formed. Body mass index (BMI) and waist-hip ratio (WHR) were calculated. Patients reporting physical activity (walking, Nordic walking, swimming, cycling, other) $\geq 150$ minutes per week were classified as "physically active". The study was conducted in autumn and winter (September-December). All participants received precise information about the aims and procedures of the study and signed an informed consent form. The procedures were conducted according to the Declaration of Helsinki (revised 2000). The study was approved by the Ethics Committee of the Medical University of Lodz, Poland.

\section{Statistical analysis}

Descriptive statistics were presented with standard deviation (SD) and mean, categorical variables as number of subjects and percentage with $95 \%$ confidence intervals $(95 \% \mathrm{Cl})$; Pearson chi-square test $\left(\chi^{2}\right)$ was used to compare the groups of categorical variables. A $p$-value $<0.05$ was set as statistically significant.

\section{Results}

The group characteristics $(n=110)$ are presented in Table 1. In the questionnaire, those examined reported: DM in $19 \%$ $(n=21)$; dyslipidemia $43.6 \%(n=48)$; CVD 68.2\% $(n=75)$. Physical activity was reported by $80.9 \%(n=89)$, and out of these, $65.5 \%(n=72)$ reported $>150$ minutes/week. The results of the laboratory tests revealed hyperglycemia in $44.5 \%(n=49)$; abnormal total cholesterol (Ch) 63.6\% ( $n=70)$; abnormal HDL $10.9 \%(n=12)$; abnormal TG in $22.7 \%(n=25)$. Vitamin D deficiency $(25(\mathrm{OH}) \mathrm{D}<30 \mathrm{ng} / \mathrm{ml} ;<75 \mathrm{nmol} / \mathrm{l})$ in $84.5 \%(n=93)$ (Table 2); extreme deficiency $(25(\mathrm{OH}) \mathrm{D}<10 \mathrm{ng} / \mathrm{ml} ;<25 \mathrm{nmol} / \mathrm{l})$ in $6.3 \%(n=7)$ (Table 2$)$. No abnormal PTH results.

\begin{tabular}{|c|c|c|c|c|}
\hline Parameter & & Men & Women & Total \\
\hline Age & mean (SD) & $70.9(7.2)$ & $67.7(5.7)$ & $68.3(6.1)$ \\
\hline Height & mean (SD) & $1.8(0.1)$ & $1.6(0.0)$ & $1.6(0.1)$ \\
\hline Height & $\min ; \max$ & $1.7 ; 1.9$ & $1.5 ; 1.7$ & $1.5 ; 1.9$ \\
\hline Weight & mean (SD) & $87.9(12.2)$ & $70.6(10.3)$ & $74.1(12.7)$ \\
\hline Weight & $\min ; \max$ & $58.2 ; 105.0$ & $51.0 ; 99.0$ & $51.0 ; 105.0$ \\
\hline BMI & mean (SD) & $28.2(3.7)$ & 27.2 (3.9) & $27.4(3.8)$ \\
\hline $\mathrm{BMI}$ & $\min ; \max$ & $20.1 ; 34.2$ & $19.5 ; 36.8$ & $19.5 ; 36.8$ \\
\hline Waist circumference & mean (SD) & $99.1(11.5)$ & $86.0(10.5)$ & $88.7(11.9)$ \\
\hline Waist circumference & $\min ; \max$ & $70.0 ; 117.0$ & $66.0 ; 112.0$ & $66.0 ; 117.0$ \\
\hline Hip circumference & mean (SD) & $99.7(7.5)$ & $104.4(8.4)$ & $103.5(8.4)$ \\
\hline Hip circumference & $\min ; \max$ & $82.0 ; 114.0$ & $80.0 ; 126.0$ & $80.0 ; 126.0$ \\
\hline WHR & mean (SD) & $1.0(0.1)$ & $0.8(0.1)$ & $0.9(0.1)$ \\
\hline WHR & $\min ; \max$ & $0.8 ; 1.3$ & $0.7 ; 1.1$ & $0.7 ; 1.3$ \\
\hline SBP & mean (SD) & $134.8(13.8)$ & $127.3(15.7)$ & $128.8(15.6)$ \\
\hline SBP & $\min ; \max$ & $115.0 ; 160.0$ & $85.0 ; 170.0$ & $85.0 ; 170.0$ \\
\hline DBP & mean (SD) & $78.9(7.1)$ & $75.7(9.2)$ & $76.3(8.9)$ \\
\hline DBP & $\min ; \max$ & $65.0 ; 90.0$ & 50.0; 95.0 & 50.0; 95.0 \\
\hline Total cholesterol (Ch) & mean (SD) & $188.4(38.8)$ & $214.3(42.9)$ & 209.1 (43.2) \\
\hline $\mathrm{Ch}$ & $\min ; \max$ & $126.0 ; 278.0$ & $134.0 ; 304.0$ & $126.0 ; 304.0$ \\
\hline Triglycerides (TG) & mean (SD) & $121.7(67.7)$ & $116.1(46.1)$ & $117.2(50.8)$ \\
\hline TG & $\min ; \max$ & $53.0 ; 381.0$ & $42.0 ; 249.0$ & $42.0 ; 381.0$ \\
\hline High-density lipoproteins (HDL) & mean (SD) & $48.3(14.8)$ & $66.8(15.5)$ & $63.1(17.0)$ \\
\hline HDL & $\min ; \max$ & $24.0 ; 90.0$ & $35.0 ; 117.0$ & $24.0 ; 117.0$ \\
\hline Glycemia & mean (SD) & $101.9(12.9)$ & $101.2(16.2)$ & $101.3(15.6)$ \\
\hline Glycemia & $\min ; \max$ & $81.0 ; 137.0$ & $82.0 ; 158.0$ & $81.0 ; 158.0$ \\
\hline Parathormone (PTH) & mean (SD) & $54.9(27.0)$ & $42.4(14.9)$ & $46.2(20.3)$ \\
\hline
\end{tabular}

Min - minimum; max - maximum; SBP - systolic blood pressure, DBP - diastolic blood pressure. 
Hypertension (HA) was revealed in $68.2 \%(n=75)$. Overweight and obesity prevalence in the group is presented in Table 3. A significant correlation between vitamin $D$ serum deficiency and visceral obesity was found $(p=0.02)$ (Table 4$)$. No correlation was found with BMI, physical activity, lipid profile, diabetes or cardiovascular diseases.

\begin{tabular}{|l|l|l|l|}
\hline \multicolumn{4}{|l|}{ Table 2. Vitamin D serum concentration in the group $(\boldsymbol{n}=110)$} \\
\hline Results & Total (\%) & Males (\%) & Females (\%) \\
\hline Normal result* & $17(15.45)$ & $3(13.64)$ & $14(15.91)$ \\
\hline Deficiency & $93(84.54)$ & $19(86.36)$ & $74(84.09)$ \\
\hline Extreme deficiency** & $7(6.36)$ & 0 & $7(7.95)$ \\
\hline
\end{tabular}

*Normal result $-25(\mathrm{OH}) \mathrm{D}>30 \mathrm{ng} / \mathrm{mL}$; **extreme deficiency - 25(OH)D $<10 \mathrm{ng} / \mathrm{mL}$.

Table 3. Overweight and obesity in the group according BMI, IDF and NCEP ATPIII criteria

\begin{tabular}{|l|l|l|l|l|}
\hline & Number & Percentage & $\begin{array}{l}\text { Males } \\
n(\%)\end{array}$ & $\begin{array}{l}\text { Females } \\
n(\%)\end{array}$ \\
\hline Obesity & \multicolumn{5}{|l|}{} \\
\hline BMI* & 30 & $\mathbf{2 7 . 5 2 \%}$ & $8(36.4 \%)$ & $22(25.3 \%)$ \\
\hline IDF** & 53 & $\mathbf{4 8 . 1 8 \%}$ & $16(72.7 \%)$ & $37(42 \%)$ \\
\hline ATP III** & 43 & $\mathbf{4 4 . 0 3 \%}$ & $11(50 \%)$ & $37(42 \%)$ \\
\hline Overweight & \multicolumn{5}{|l}{} \\
\hline BMI & 46 & $\mathbf{4 2 . 2 \%}$ & $12(54.5 \%)$ & $34(38.6 \%)$ \\
\hline WHR & 48 & $\mathbf{4 4 . 0 3 \%}$ & $14(63.6 \%)$ & $34(38.6 \%)$ \\
\hline
\end{tabular}

${ }^{*}$ BMI obesity criteria: $\geq 30 \mathrm{~kg} / \mathrm{m}^{2} ; * *$ IDF obesity criteria (for Europid population): waist circumference $\geq 94 \mathrm{~cm}$ in males; $\geq 80 \mathrm{~cm}$ in females; ***ATPIII obesity criteria: waist circumference: $>102 \mathrm{~cm}$ in males; $>88$ $\mathrm{cm}$ in females.

\section{Discussion}

The results of our study showed a high prevalence (84.5\%) of vitamin $\mathrm{D}$ deficiency in the examined group of elderly patients. This is comparable to the results of other Polish studies; e.g. Stolarczyk et al., conducted on 107 post-menopausal females, in which only $6-17 \%$ of the patients (depending on the season) had an adequate serum 25(OH)D level [16]. It is also comparable to the results of the research by Napiórkowska et al. performed on a group of 274 women, aged $60-90$, showing a high prevalence $(96 \%)$ of low $25(\mathrm{OH}) \mathrm{D}$ concentration in an urban population of elderly females in Poland [17]. The results also correspond with world data, estimating that nearly $90 \%$ of the European adult population are vitamin D deficient/insufficient [10].

We found a significant correlation between vitamin $D$ serum deficiency and obesity $(p=0.02)$ in patients aged $>60$.

Due to global vitamin $\mathrm{D}$ deficiency and the probable relationship between vitamin D levels and CVD risk factors, special attention is paid to the correlations between 25(OH)D and elements of metabolic syndrome (MS). At times, the results of studies considerably differ from each other or are not consistent [18]. There is also a hypothesis of a " $\mathrm{U}$ " or " $\mathrm{J}$ "-shaped association of serum vitamin D concentration and CVD risk (at low and higher vitamin $D$ levels, the CVD risk increases) [1]. There is growing evidence for a strong association between vitamin D deficiency and MS components [19]. The results of our study also confirm the correlation between $25(\mathrm{OH}) \mathrm{D}$ deficiency and obesity.

Obesity seems to be a pathology closely associated with vitamin $D$ deficiency. Evidence for this comes from research conducted on small, as well as large, groups of patients. Vimaleswaran et al. research ( $>42,000$ patients) proved that there is a strong relation between obesity and lower serum vitamin $D$ and suggested that obesity is the causal risk factor. The study revealed that an increase of BMI was associated with a 25(OH)D decrease [11]. An Australian study (> 11,000 patients) also confirmed that the prevalence of vitamin $D$ deficiency significantly increased in obese persons with age [20]. There are observations on correlations of vitamin $D$ deficiency and increased adiposity. In a retrospective study on hospital patients (2009-2011), Guasch et al. found that low 25(OH)D levels are associated with a higher risk of MS and atherogenic dyslipidemia [21]. The Framingham Heart Study also revealed a strong association between vitamin D concentration and subcutaneous and visceral adiposity [22]. Another study, performed in Puerto Rico, revealed among 94 overweight and obese adults a significant inverse correlation of $25(\mathrm{OH}) \mathrm{D}$ with percentage of body fat. Obese patients (41.4\%) were vitamin $\mathrm{D}$ deficient compared to normal weight (33.9\%) and overweight individuals $(30.3 \%)(p<0.05)$ [14].

Some recent interventional studies confirm the importance of vitamin D in lowering obesity complications. Carrillo et al. proved that vitamin D supplementation in overweight and obese adults during resistance training led to an early improvement in peak power, as well as the fact that an elevated vitamin $\mathrm{D}$ level was connected with lower WHR [23].

\begin{tabular}{|l|l|l|l|}
\hline \multicolumn{5}{|l|}{ Table 4. Associations of vitamin D deficiency and the examined parameters in the group } \\
\hline Parameter & chi $(\chi)^{2}$ Pearson test & contingency coefficient & level of significance $(p)$ \\
\hline Obesity (IDF)** & 4.894541 & 0.2063984 & $\boldsymbol{p}=0.02$ \\
\hline Obesity(ATPIII)*** & 3.437050 & 0.1748390 & $p=0.06$ \\
\hline $\begin{array}{l}\text { Obesity (ATPIII) } \\
\text { in females }\end{array}$ & 5.445196 & 0.2426971 & $p=0.019$ \\
\hline Overweight (BMI) & 0.0086816 & 0.0089242 & $p=0.92$ \\
\hline Obesity (BMI) & 2.507305 & 0.1499519 & $p=0.11$ \\
\hline WHR & 3.437050 & 0.1748390 & $p=0.06$ \\
\hline Ch & 0.2012741 & 0.0427367 & $p=0.65$ \\
\hline TG & 0.2954943 & 0.0517602 & $p=0.58$ \\
\hline HDL & 0.0151458 & 0.0117333 & $p=0.90$ \\
\hline Creatinine & 0.0695762 & 0.0251418 & $p=0.79$ \\
\hline Glycemia & 0.0923881 & 0.0289687 & $p=0.76$ \\
\hline PTH & 0.1415252 & 0.0358461 & $p=0.70$ \\
\hline HA & 0.1982498 & 0.0474107 & $p=0.65$ \\
\hline Physical activity & 0.6987031 & 0.0794466 & $p=0.40$ \\
\hline
\end{tabular}

**IDF obesity criteria (for Europid population): waist circumference $\geq 94 \mathrm{~cm}$ in males, $\geq 80 \mathrm{~cm}$ in females; ${ }^{* * *}$ ATPIII obesity criteria: waist circumference: $>102 \mathrm{~cm}$ in males, $>88 \mathrm{~cm}$ in females. 
On the other hand, one should take note of the study by Kienreich et al., summarizing the most recent data on the involvement of vitamin $D$ deficiency in the development of major CVD risk factors (HA, obesity, dyslipidemia, DM, chronic kidney disease, endothelial dysfunction). No significant relationship of vitamin $D$ and obesity was found, but it was concluded that vitamin D deficiency is an independent CVD risk factor [24].

There are multiple observations concerning the association of vitamin D status and insulin sensitivity. One of the most important is a longitudinal study (17-year follow-up period), which revealed a $40 \%$ reduction of the risk of DM development in people with $25(\mathrm{OH}) \mathrm{D}>28 \mathrm{ng} / \mathrm{ml}$ at baseline [25]. There is also research showing an inverse correlation of vitamin D concentration and the risk of progression to prediabetes or DM, as well as studies showing a correlation of $25(\mathrm{OH}) \mathrm{D}$ with insulin sensitivity [26]. However, there are also studies whose results do not support such an association [27]. Badawi et al. (1,928 Canadian patients) found an inverse relationship between IR and the plasma vitamin D level. It was also revealed that the supplementation of vitamin D may help in preventing IR [28]. Vitamin D deficiency is thought to influence the pathogenesis of DM by affecting either insulin sensitivity, $\beta$-cell function, or both [28].

One of the other MS elements - dyslipidemia (high TG, low $\mathrm{HDL}$ ) - is considered to be associated with vitamin $\mathrm{D}$ deficiency [29]. In the NHANES III study $(8,421$ participants, $>20$ years old), a significant inverse correlation was found between higher 25(OH)D and hypertriglyceridemia, hyperglycemia and abdominal obesity. Generally, the results showed a higher prevalence of MS in people with a lower vitamin D serum concentration [30].

Vitamin D deficiency is a risk factor for hypertension; however, randomized controlled trials revealed mixed effects of vitamin D supplementation on blood pressure (BP) [31]. One of the results of the NHANES III study confirmed the inverse association of $25(\mathrm{OH}) \mathrm{D}$ levels and $\mathrm{BP}$, especially strong in people aged $>50$ [18]. Owing to the performed meta-analysis, Kunutsor et al. revealed a significant inverse correlation between $25(\mathrm{OH}) \mathrm{D}$ and the risk of HA [32]. Vitamin D negatively regulates RAAS [8]. Interesting results of a meta-analysis were reported by Wu et al., in which it was found that vitamin $D$ supplementation was associated with a significant reduction of systolic BP, but there was no evidence for diastolic BP reduction [33]. On the contrary, no impact of vitamin D supplementation on the control of HA was found in the recently published DAYLIGHT trial [34]. There are also observational studies concerning the association of lower
25(OH)D and a higher incidence of CVD and all-cause mortality $[35,36]$. Another important observation was presented by Grandi et al., who reported a CVD mortality risk increase by $83 \%$ in subjects with low 25(OH)D [37]. On the other hand, a recent systematic review of 40 randomized control trials showed that vitamin $D$ supplementation to raise serum $25(\mathrm{OH}) \mathrm{D}$ concentrations above $50 \mathrm{ng} / \mathrm{ml}$ did not reduce the relative risk of coronary heart disease in community dwellers by more than $15 \%$ [1].

In another systematic review by Chowdhury et al. involving 22 studies (30,716 patients), it was found that supplementing vitamin $D_{3}$ resulted in a modest $11 \%$ relative risk reduction for all-cause mortality [3].

It should be emphasized that some meta-analyses clearly indicate that, in the elderly mortality and morbidity associated with a body excess increase at BMI $>30 \mathrm{~kg} / \mathrm{m}^{2}$ [38]. Therefore, all factors potentially influencing obesity in the elderly should be carefully analyzed.

Our study was performed in a group of 110 elderly patients, out of which $20 \%$ were male. Vitamin D deficiency was high in the whole group (84.5\%), with extreme deficiency in a few patients, mainly females. This may correspond with Novara Atherosclerosis Study Group data, which showed gender differences for vitamin $D$ status, with a higher rate of deficiency especially occurring in post-menopausal females. Verdoia et al. found that the female gender was associated with lower vitamin $D$ levels and independently associated with severe vitamin $D$ deficiency $(p<0.001)$ [39].

To summarize, despite multiple data, the question of the role of vitamin D in human metabolism, as well as CVD pathogenesis, is still not fully explained, especially in the context of gender differences. Therefore, it requires further research. One of the most frequently found relationships is the association of vitamin $D$ deficiency and obesity. This observation was also confirmed by the results of our study.

\section{Conclusions}

Vitamin D deficiency was found to be highly prevalent in the examined group of elderly patients. The study revealed a strong correlation between vitamin $D$ deficiency and visceral obesity. Vitamin D supplementation may supposedly contribute to the prevention of obesity and its treatment. The problem needs further investigation on a larger group of patients.

Source of funding: This work was funded by the Medical University of Lodz (statute-based activity).

Conflict of interest: The authors declare no conflict of interests.

\section{References}

1. Harikrishnan S, Sanjay G. Vitamin D and cardiovascular disease - have we found the answers? Indian Heart J 2015; 67(1): 11-13.

2. Marcinowska-Suchowierska E, Walicka M. Niedobór witaminy D - narastający problem społeczny. Fam Med Prim Care Rev 2009; 11(3): 691-698 (in Polish).

3. Chowdhury R, Stevens S, Ward H, et al. Circulating vitamin D, calcium and risk of cerebrovascular disease: a systematic review and meta-analysis. Eur J Epidemiol 2012; 27: 581-591.

4. WHO. Obesity [cited 1.06.2017]. Available from URL: www.who.int/topics/obesity/en.

5. International Obesity Task Force. The Global Challenge of Obesity and the International Obesity Task Force [cited 1.06.2016]. Available from URL: http://www.iuns.org/the-global-challenge-of-obesity-and-the-international-obesity-task-force/.

6. Jarosz M, Rychlik E. Otyłość - problem coraz bardziej powszechny. Fam Med Prim Care Rev 2009; 11(3): 647-653 (in Polish).

7. Zdrojewski T, Grodzicki T, Więcek A, et al. Aspekty medyczne, psychologiczne, socjologiczne i ekonomiczne starzenia się ludzi w Polsce. Projekt PolSenior [cited 3.06.2016]. Available from URL: http://polsenior.iimcb.gov.pl/monografia (in Polish).

8. Thompson J, Nitiahpapand R, Bhatti P, et al. Vitamin D deficiency and atrial fibrillation. Int J Cardiol 2015; 184C: 159-162.

9. Endocrine Society. Evaluation, treatment, and prevention of vitamin D deficiency: an endocrine society clinical practice guideline. $J$ Clin Endocrinol Metabol 2011; 96(7): 1911-1930.

10. Ginde AA, Liu MC, Camargo CA Jr. Demographic differences and trends of vitamin D insufficiency in the US population, 1988-2004. Arch Intern Med 2009; 169(6): 626-632.

11. Vimaleswaran KS, Berry DJ, Lu C, et al. Causal relationship between obesity and vitamin D status: bi-directional Mendelian randomization analysis of multiple cohorts. PLoS Med 2013; 10: e1001383, doi: 10.1371/journal.pmed.1001383.

12. Song Q, Sergeev IN. Calcium and vitamin D in obesity. Nutr Res Rev 2012; 25: 130-141.

13. Martini LA, Wood RJ. Vitamin D status and the metabolic syndrome. Nutr Rev 2006; 64: 479-486. 
14. González L, Ramos-Trautmanna G, Díaz-Luquis GM, et al. Vitamin D status is inversely associated with obesity in a clinic-based sample in Puerto Rico. Nutr Res 2015; 35(4): 287-293.

15. GUS. Stan Zdrowia Ludności Polski w 2009 r. [cited 3.06.2016]. Available from URL: www.stat.gov.pl/cps/rde/xbcr/gus/PUBL_ZO_stan_ zdrowia_2009.pdf.

16. Stolarczyk A, Horvath A, Szczechura M, et al. High prevalence of vitamin D insufficiency in community-dwelling postmenopausal Polish women. Przegl Menop 2014; 13(5): 289-292.

17. Napiórkowska L, Budlewski T, Jakubas-Kwiatkowska W, et al. Prevalence of low serum vitamin D concentration in an urban population of elderly women in Poland. Pol Arch Med Wewn 2009; 119(11): 699-703.

18. Prasad P, Kochhar A. Interplay of vitamin D and metabolic syndrome: a review. Diab Met Syndr: Clin Res Rev 2015; 10(2): 105-112, doi: http://dx.doi.org/10.1016/j.dsx.2015.02.014.

19. Mandarino NR, Junior DD, Salgano JV, et al. Is vitamin D deficiency a new risk factor for cardiovascular disease? Open Cardiovasc Med J 2015; 9: 40-49.

20. Daly RM, Gagnon C, Lu ZX, et al. Prevalence of vitamin D deficiency and its determinants in Australian adults aged 25 years and older: a national, population-based study. Clin Endocrinol (Oxford) 2012; 77(1): 26-35.

21. Guasch A, Bulló M, Rabassa A, et al. Plasma vitamin D and parathormone are associated with obesity and atherogenic dyslipidemia: a cross-sectional study. Cardiovasc Diabetol 2012; 11: 149-160.

22. Cheng S, Massaro J, Fox C, et al. Adiposity, cardiometabolic risk, and vitamin D status: the Framingham heart study. Diabetes 2010; 59: 242-248.

23. Carrillo A, Flynn M, Pinkston C, et al. Impact of vitamin D supplementation during a resistance training intervention on body composition, muscle function, and glucose tolerance in overweight and obese adults. Clin Nutr 2013; 32: 375-381.

24. Kienreich K, Tomaschitz A, Verheyen N, et al. Vitamin D and cardiovascular disease. Nutrients 2013; 5(8): 3005-3021.

25. Pittas AG, Harris SS, Stark PC. The effects of calcium and vitamin D supplementation on blood glucose and markers of inflammation in nondiabetic adults. Diabetes Care 2007; 30: 980-986.

26. Tsur A, Feldman B, Feldhammer I, et al. Decreased serum concentrations of 25 -hydroxycholecalciferol are associated with increased risk of progression to impaired fasting glucose and diabetes. Diabetes Care 2013; 36(5): 1361-1367.

27. George PS, Pearson ER, Witham MD. Effect of vitamin D supplementation on glycaemic control and insulin resistance: a systematic review and metaanalysis. Diabetes Med 2012; 29: 142-150.

28. Badawi A, Sayegh S, Sadoun E, et al. Relationship between insulin resistance and plasma vitamin D in adults. Diab Met Syndr Obes 2014; 7: 297-313.

29. Miñambres I, Sánchez-Quesada JL, Sánchez-Hernández J, et al. Vitamin D concentrations in familial combined hyperlipidemia: effects of lipid lowering treatment. Diabetol Metab Syndr 2014; 6: 7, doi: 10.1186/1758-5996-6-7.

30. Ford E, Ajani U, Mcguire L, et al. Concentrations of serum vitamin D and the metabolic syndrome among U.S. adults. Diabetes Care 2005; 2: 1128-30.

31. Pilz S, Gaksch M, Kienreich K, et al. Effects of vitamin D on blood pressure and cardiovascular risk factors. A randomized controlled trial. Hypertension 2015; 65(6): 1195-1201, doi: 10.1161/HYPERTENSIONAHA.115.05319.

32. Kunutsor SK, Apekey TA, Steur M. Vitamin D and risk of future hypertension: meta-analysis of 283,537 participants. Eur J Epidemiol 2013; 28: 205-21.

33. Wu SH, Ho SC, Zhong L. Effects of vitamin D supplementation on blood pressure. South Med J 2010; 103: 729-737.

34. Pankaj $A$, Song $Y$, Dusek J, et al. Vitamin D therapy in Individuals with prehypertension or hypertension: the DAYLIGHT trial. Circulation 2015; 131(3): 254-262, doi: 10.1161/CIRCULATIONAHA.114.011732.

35. Zittermann A, lodice $\mathrm{S}$, Pilz $\mathrm{S}$, et al. Vitamin $\mathrm{D}$ deficiency and mortality risk in the general population: a meta-analysis of prospective cohort studies. Am J Clin Nutr 2012; 95: 91-100.

36. Schottker B, Ball D, Gellert C, et al. Serum 25-hydroxyvitamin D levels and overall mortality. A systematic review and meta-analysis of prospective cohort studies. Ageing Res Rev 2012; 12: 708-718.

37. Grandi NC, Breitling LP, Brenner H. Vitamin D and cardiovascular disease: systematic review and meta-analysis of prospective studies. Prev Med 2010; 51: 228-233.

38. Mathus-Vliegen EM. Obesity and the elderly. J Clin Gastroenterol 2012; 46(7): 533-544.

39. Verdoia M, Schaffer A, Barbieri L, et al. Novara Atherosclerosis Study Group (NAS). Impact of gender difference on vitamin D status and its relationship with the extent of coronary artery disease. Nutr Metab Cardiovasc Dis 2015, doi: http://dx.doi.org/10.1016/j. numecd.2015.01.009.

Tables: 4

Figures: 0

References: 39

Received: 22.02.2017

Revised: 21.03.2017

Accepted: 22.03.2017

Address for correspondence:

Małgorzata Koziarska-Rościszewska, MD, PhD

Klinika Nefrologii, Nadciśnienia Tętniczego i Medycyny Rodzinnej UM

ul. Żeromskiego 113

90-549 Łódź

Polska

Tel.: +48 42 63-93-750

E-mail: malgorzata.koziarska-rosciszewska@umed.lodz.pl 